\title{
18
}

\section{PRME WORKING GROUP ON ANTI-CORRUPTION}

\author{
Matthias Kleinhempel
}

\subsection{Introduction}

The PRME Anti-Corruption Working Group was established in December 2008 to develop curriculum and teaching methods for including anticorruption subject matter in business and liberal arts curricula at business schools and universities.

The Anti-Corruption Working Group members are experts on the subject matter with longtime research and teaching experience at universities around the world. They teach and research at universities in the United States, Poland, Germany, Switzerland, South Africa, India, Vietnam, Argentina, and more countries. Some of them have direct experience in establishing anti-corruption centers in Argentina, South Africa, and Switzerland. They have utilized two complementary approaches in achieving their objectives: (1) a vertical strategy - implementing open anti-corruption programs for business and nonbusiness organizations and (2) a horizontal strategy that seeks inclusion of business ethics subject matter in corporate governance, policy, and strategy courses, and in relevant liberal arts subjects. 
Anti-corruption has to be taught at business schools: that's where the future leaders of organizations are trained. And they are the ones who set the tone of how business will be performed by their organizations. The fight against corruption cannot be won without them.

The Working Group financed by a grant from the Siemens Integrity Initiative, initial effort was to devise a tool kit for teaching anti-corruption in business schools with a focus on the utilization of four core liberal arts subjects: (1) Ethics, (2) Economics, (3) Law, and (4) Behavioral Sciences to develop decision-making models for recognizing, confronting, and resolving ethical dilemmas including most importantly - corruption in all its forms. The Working Group divided its labors into three categories: (1) Course Content, (2) Teaching Methods, and (3) Measuring Program Success. Their findings are summarized below.

\subsubsection{Course content}

Evidence that the business world has become more ethical since ethics became part of the business curriculum is not easily found but this does not mean that ethics cannot be a vital and effective part of the business education. Thus the right question is to ask is how best to teach it. Teaching business ethics must contend with the skeptical view that while moral reasoning can be taught, the character and habits of mind that moral behavior requires cannot be learned in the classroom.

Responding to this challenge necessitates focus on all of the three key elements of the business ethics project: (1) content, (2) teaching methods, and (3) measuring effectiveness:

Before discussing subject matter, we need to determine for whose benefit the course is being taught. Is it the institutions that will hire our graduates, the students, or the global community? The answer is all of them. Each of these entities has its own needs and expectations. Both private sector and the increasing number of nonprofit and NGO institutions that seek job applicants with business degrees value the business ethics conversation:

(1) Employers want employees who acknowledge the importance of organizational risk management systems through the maintenance of effective compliance systems that can prevent and detect actual or potential violations of law. Further, they seek managers who are conversant with the emerging global compliance regime; (2) Students seek additional analytic 
and decision making skills that will enhance their career prospects for achieving leadership positions; and (3) the global community wants a new generation of leaders that can exercise political and economic power with a confident and well defined sense of civic virtue.

Leadership is the common denominator of these three consumer needs. The functional business school subjects offer training in finance, marketing, and administration - all essential and worthy management vocations that require high levels of diligence, skill, and experience. Ethics is the course where the leaders of these and other functional areas are educated. Critics argue that the business ethics curriculum focuses primarily on rules and incentives. This subject matter does serve a useful but limited purpose. While rules (law) and misaligned incentives (market failure) are tools for identifying and framing ethical issues, the next and critical phase in resolving ethical dilemmas is the proper exercise of choice between more than one defensible alternatives. Making the right choices in these kinds of situations is what leaders are paid to do. What are their necessary habits of mind?

The purpose of the business ethics curriculum is to develop leaders capable of identifying problems, recognizing alternatives, and making wise decisions with significant impact in the global business community. In this context, leadership is the effective balancing and coordination between purpose and power. Objectives must not exceed the resources available to achieve them. That principle though often violated is generally understood. The less recognized disequilibrium occurs when power seeks to define purpose. Ethical leadership recognizes that power is most effectively exercised to achieve narrow and well defined objectives.

Many of the worst historical and business calamities have resulted from situations where resources rather than the articulation of shared principles and interests defined the objectives. Doing something because you can is not an ethical choice. In this context, it is useful to reflect on an historical figure whose name is seldom mentioned as an ethical role model. Yet he understood that successful leadership entails an understanding that power is most effectively used in combination with restraint. Bismarck was the master practitioner of this maxim. For example, in resisting pressure for African colonial expansion (not entirely successfully but more so than other contemporary European leaders), he said to one proponent, "Your map of Africa is very fine, but my map of Africa is here in Europe" (Gordon A. Craig, Germany, 1866-1945, Oxford University Press, 1978, pp. 116-117). 
In sum, rules and incentives are useful in the business ethics curriculum because they help the student to identify issues and frame questions using a vocabulary that is useful to them. While essential, these are only the first two steps in a business ethics education. Resolution of these dilemmas requires virtue, wisdom, and character.

We are back to where we began. Can these traits be taught? Perhaps not; but they can certainly be admired and recognized as the standard for making choices that raise ethical issues In this regard, the focus is the three major ethical schools of thought (Virtue, Deontology, Consequentialism) and how best to resolve the conflicting outcomes that they may prescribe through the exercise of virtue, wisdom, and character.

In doing so, examples from political and military as well as business history are highly relevant. We should begin to include more examples of institutional leaders did that right thing and fewer autopsies of why companies collapsed as a result of ethical lapses. In many cases, those businesses probably would have failed anyway. People who make ethical mistakes do not necessarily have infallible judgment in all other areas. The right choice is more likely to speak for itself. The wrong one has a multiplicity of explanations.

\subsubsection{Teaching methods}

Ethics teaching methods have changed little in 2500 years and for good reason - they work. The Socratic method requires students to be morally articulate and to respond to Pascal's challenge that we "think as men of action [and] act as men of thought." While the rest is commentary, there remain issues to be discussed:

Course Materials: materials should include (1) core readings for both the course (e.g., market failure) and the individual subject under discussion in a particular class (e.g., insider trading, discrimination), (2) case studies of problems/successes in business journals and newspaper articles, and (3) scenarios of ethical dilemmas based on real-life situations that can be used for classroom discussion. Scenarios which are optimally no more than a page of text are often confused with case studies that typically have a retrospective narrative and don't confront the reader with decisions that must be made.

Pedagogical Style: A combination of lectures, role play, debate, and scenario discussion are appropriate. In some countries, students are not accustomed to the Socratic approach; but patience and effort are usually successful in getting them to use it. Arrogant CEO and consultant style bluster is 
counterproductive. The message needs to be that both teacher and student are collaborating in a search for truth. They are not going to get there. The measure of success is how close they can get to it by working together.

Practical Wisdom: At least one class should feature a practitioner who can speak from current on the ground experience (e.g., compliance specialist, defense or prosecuting attorney, governmental official). There should be a bias against felons and self-proclaimed whistleblowers who have reinvented themselves as "motivational speakers" and, if selected, they should not be compensated.

Intensive Class/Class Size: Intensive classes work best. Although smaller numbers of participants do not generate higher participation rates, they result in significantly greater student satisfaction. If feasible, smaller classes should be offered to students. If the entry or course requirements are different, it might be possible to run a few small classes in addition to the large ones.

Student "Professionalism": The recent initiative to achieve a transition from class participation and professionalism as a grade component highlights the difference between teaching business ethics and management subjects. In both cases, people need to show up on time but thereafter, requirements diverge. In the first instance, students are expected to be prepared with answers/plans that they can defend against relentless attack from professors and their classmates. In ethics, the emphasis is on being able to ask the right questions in a nonthreatening environment where all efforts are encouraged and valued.

\subsubsection{Measuring program progress}

The test for individual course success and for the business ethics discipline as a whole is what it has achieved as a platform for engaging the entire community in a collaborative learning exercise. Are senior executives willing to speak to and teach classes? Is the school able to convene conferences that bring together multiple academic, private-sector, not-for-profit, governmental and nongovernmental organization representatives? Do these institutions participate in a subject matter related internship program? In the final analysis, business ethics course and disciple achievement cannot be determined by whether the world has become more ethical - it will be judged by how many institutions and persons of "fundamentally different views" have been enlisted in this common pursuit.

The PRME web page and Toolkit has now been used in numerous business schools around the world: 


\subsection{Using the Toolkit in business schools: some perspectives}

Warren Buffett has famously said that success in business requires three qualities: (1) Competence, (2) Passion, and (3) Integrity, and, that without the third, the first two do not count.

In other words, that ethics and values are an essential part of the business decision-making process.

Since Enron, World Com, and other famous scandals, business schools pay more attention to ethics as a subject matter. They have been blamed for having educated MBA students as monsters - executives driven only by financial motivation instead of leaders with ethical standards. Business schools started to react by introducing ethics courses or modules in their MBA programs with mixed results. Accreditation Agencies as the AACSB require business schools to incorporate business ethics classes in their MBA programs.

There is a common understanding that students have to be (better) prepared for the dilemmas they will have to confront in their professional life almost on a daily basis. What should business schools be aiming at: teaching them what it takes not to end the day in jail or enlightening businessmen to observe ethical principles beyond the legal minimum? Should the focus be on a practical approach (focused on law and rules) or a more abstract approach (focused on reasoning with principles) sustaining that there is no such field as "business ethics" as such (Kevin T. Jackson, Breaking down the barriers: Bringing initiatives and reality into business ethics education, Journal of Management Education, Feb. 2006, 30, 1 pp. 65-89).

Students and faculty agree on one point: students do not want to be involved in an Enron-type scandal and the business schools do not want to confer degrees on business "leaders" who become embroiled in scandals where decision-makers failed to recognize the consequences of bad ethical choices.

But recognizing that as important is one thing and finding the best way to effectively channel it to students' minds is another, a much more complex one.

Thus, it is not surprising that for years now the discussion in academia goes high on how to do it best. These discussions are far from over and seemingly every business school follows its own recipe.

These concerns have given rise to an on-going conversation on how best to improve students' facility for making ethical decisions in the same way that the business curriculum improves a student's ability to make choices in finance, marketing, and administration. 
The first question to ask is, Can ethics be taught to students whom to a significant degree have more fully formed opinions on ethics than they do on other subjects in the business curriculum? Do entering business school students arrive with their values and ethical compass formed during childhood, and instilled by family and friends, and primary school education?

A key question that arises in this context is whether business ethics should be taught as a stand-alone course of varying length, from few classes to a full-semester-long course.

Others prefer a more integrated approach and consider that business ethics should be taught in every course, interwoven into the respective teaching on Finance, Marketing, Corporate Governance, and so on. The reasoning behind this approach is that ethics and values are part of every business decision. If every business decision has ethical consequences, they have to be discussed in the context of the various business topics and will be better understood and engrained in context than in an isolated ethics course which might even convey the wrong impression: That business ethics is an isolated topic.

The next level of academic discussion is one of pedagogical nature: which are the best teaching methods. Traditional case studies, 12 page-long plus annexes? Unilateral lectures, transmitting knowledge? Or the discussion of philosophical and sociological texts? Discussion of short cases and dilemmas? Or presenting ethical dilemmas within the context of arts, e.g. movies, theater, and literature? The debate is ongoing and most probably, all or some of these methods should be somehow combined. Lectures and interactive sessions with active individual and group participation constitute the backbone of any course taught today at business schools. The Toolkit's chapter on teaching methods lists and describes almost all of them so that they can be chosen to adapt courses and modules to regional preferences and pedagogical needs.

It is not the PRME's Anti-Corruption Toolkit's purpose to contribute to this debate (even though there are some arguments and contributions to be found in it). Without trying to recommend one way or the other, the Toolkit supports and orients the instructor to find teaching materials and methods for the main challenges he is facing in trying to effectively teach business ethics and anti-corruption. These challenges have been described by Ronald S. Sims and Edward L. Felton jr. in, Designing and delivering business ethics teaching and learning, Journal of Business Ethics 2006, 63, pp. 297-312):

1. What are the objectives or targeted learning outcomes of the course?

2. What kind of learning environment should be created? 
3. What learning processes need to be employed to achieve the goal?

4. What are the roles of the participants in the learning experience, especially the roles of the two major players - the instructor and the students?

Business schools typically face some serious constraints integrating new courses or additional sessions into their existing programs, especially MBA programs. Schedules seems to be already tight and additional time slots for teaching additional classes are nonexistent, meaning that in order to get something new in, something else has to be taken out of the program. And behind this "something," the content which has to leave or to cede - partially or totally are teaching interests which don't tend to be interested in leaving. That is one of the reasons why it is so difficult to design a short or long stand-alone course or even to disperse a significant amount of classes in different courses dedicated to other teaching objectives. Therefore the importance of the Toolkit's flexible and adaptable teaching material offering. Furthermore, the Toolkit is a valuable source for instructors who are not coming from the ethics and/or anti-corruption specialists crowd and therefore are not so familiar with the existing and dispersed teaching materials and methods but they would like anyhow to incorporate business ethics/anti-corruption in their courses.

The Toolkit doesn't take sides with any of the schools, preferring one or the other design and method of ethics education for business. It is a tool to support educators designing ethic and anti-corruption sessions and courses and provides state of the art teaching material and methods.

Talking about education at business schools, one aspect is paramount: It must be praxis-oriented, delivering analytical framework and tools as well as the required skills on how to confront corruption in real-life situations. Research shows that the most effective training elements are case-studies, dilemmas and, to a certain extent, role-playing.

But training has - independently from its effectiveness per se - much less impact than the organizational support (Improving Ethical Outcomes: The Role of Ethics Training; ERC Ethics Resource Center, 2008). The conclusion to draw from this insight involves Business Schools and companies along: Ethics and anti-corruption education has not only to be delivered for its direct impact on employees (or future employees) but to foster the required organizational support, meaning essentially a strong anti-corruption company culture. It all translates into leadership and leadership courses for executives in Business Schools. The Toolkit is a valuable source to integrate anti-corruption and ethics topics into these courses. 
Design and methods for teaching anti-corruption courses is complex. Corruption has many facets and comes along in regionally, sector-, and function-specific forms. A common ground and language has to be found to assure discussions without confusions. Furthermore, in an ever more globalized world, students in MBA programs and participants in executive education programs are more and more diverse, with different nationalities and cultural backgrounds. The Toolkit with its sources from different continents, developed and emerging markets, brings an important advantage for instructors as it provides an equally diverse teaching material. At the same time, the teaching content and its methods will have to be adapted to special audiences. Specialized MBA courses will require different designs and teaching methods and in executive education the challenge of adapting methods and contents is even higher: Different age groups, different previous management experiences and positions, and different exposures to corruption make it difficult to design the most effective course. It all depends on the target group.

The following questions arise: what has to be taken into account in preparing a course on anti-corruption and which teaching methods fit best? This last question also entails who is best equipped to teach the course: academics? Practitioners with experience in dealing with corruption, its prevention, and consequences? Each group will approach the topic differently. Both approaches are valuable. The perfect combination of deep academic analysis and real-life experience with proven tools and strategies should be searched for, but will be difficult to achieve: especially because experienced practitioners (CEOs, compliance officers, etc.) tend to be reluctant going into details regarding their experiences in this thorny field and prefer to put the focus on more general topics of their companies' anti-corruption policies and control mechanisms. But a setting with academics and practitioners will be interesting for course participants and will enrich discussions. Practitioners eventually put academic theories into perspective, preferring more hands-on and practical approaches. Academics may enrich and contribute new views to strategies and tools born in business.

The practical element is of utmost importance in business schools. Without it the education loses credibility. Joint classes with practitioners tend to be well evaluated for exactly this reason. Practitioner engagement can lead to in fruitful discussions not only with the participants, enabling learning through sharing of different points of view and experiences, making sessions more attractive through higher interactivity. In this kind of 
setting in which the academic instructor contributes the theoretical frameworks and both participants and practitioners have a framework in which they can gain a better understanding of their experiences in different sectors and levels of responsibilities in their organizations. The resulting discussions and new knowledge allow participants to reflect on them and to build their own anti-corruption strategies tailor-made to their specific needs. In the same line, sessions should be a good mix of lectures, conferences, case studies, dilemmas, and other interactive practices such as roleplaying. That is, to go from theoretical to practical content and method.

There is quite some room for business schools to improve anti-corruption culture(s), strategies, and tools beyond the PRME Anti-Corruption Toolkit implementation in MBA programs: Business schools should actively seek the dialogue and the establishment of partnerships with business sectors associations and companies in their region. They can search for and team up with partners from the anti-corruption field (i.e., U.N. Global Compact local networks, Transparency International, other NGOs, and the network of business schools that has developed the Toolkit) in order to jointly reach out to the corporate world.

In doing so they will be able not only to integrate into the Toolkit further teaching materials specific to their region and/or industry sector but also develop new ideas for a closer cooperation between academia and business in order to improve the effectiveness of their actually mostly separated anti-corruption efforts, and design and implement them. Examples for joint activities are:

- Establishment of anti-corruption research centers or anti-corruption chairs. Research in the anti-corruption field is often an extremely difficult enterprise as companies don't tend to share their experiences in the matter unless they play a positive role. That's a very understandable position, as they are not interested to harm their reputation further by being a negatively discussed subject for years to come in business schools' classrooms around the world. Business schools working closely together with executives will have better access to company information and data, and can gain their necessary trust to conduct research with sufficiently anonymized situations, resulting in valuable applied research and teaching material. The Toolkit provides the sources for choosing the adequate framework and collection of literature to build on. 
- Best business practices platforms for the exchange of experiences with practitioners (compliance officers, corporate lawyers, CFOs, etc.). The Toolkit and especially its global network of participating business schools provides the essential experiences and active support for building these platforms, which have proven extremely useful for fighting corruption in emerging markets, where the international compliance associations do not exist and local network have not been built.

- Development of training sessions and material in the form of codes of conduct, websites, videos, game simulations, and so on, for specific business sectors, companies, and their value chains. The Toolkit provides a stock of teaching material which should be further adapted to meet regional and local requirements. Business schools, jointly with practitioners, are well fitted to do this essential work: the more tailormade to local situations, the teaching material can be adapted the more it will be accepted and taken as valuable base for class discussion.

- Facilitation of collective action and integrity pacts agreements with specific business sectors or by projects along with other stakeholders (e.g., chambers of commerce, NGOs, public sector). The Toolkit also provides sources regarding collective actions and integrity pacts. They can be the starting block for business schools to facilitate these agreements, contributing to building clean (or at least cleaner) niches in business sectors, especially in emerging markets.

- Organization of conferences and seminars with leading business ethics and anti-corruption experts.

- Assistance in implementing compliance programs and other anticorruption tools. The Toolkit can enable business schools to better assist companies in planning their first steps in compliance matters such as establishing a code of conduct and implementing compliance programs because they possess the academic background and the Toolkit provides for the international framework and regulatory requirements.

All these alternatives and opportunities for business schools to work with the Toolkit beyond the MBA classroom contribute to fighting corruption more effectively: They bring academia and business together, enriching academics with real-life experience and validation opportunities for theory and enhance business practices with conceptualization allowing for broader use. 


\subsection{The Working Groups' new main project}

The next and most important step in the WGs' work aims at bringing academia and business closer together in their largely separated ways to fight corruption. The objective is creating room for them to share and combine insights from theory and practice; understanding better their concepts, positions, and challenges; and in consequence enabling them to develop effective A/C tools.

By providing best practices of existing compliance and integrity centers at universities and business schools as well as blueprints and assistance for establishing those centers, the project will assist universities/business schools in establishing and/or adapting existing academic compliance and anti-corruption centers. Running these Centers will engage local companies and key stakeholders through training, cross-industry pollination and business-academia dialogue, and dissemination of best practices to combat corruption.

Trained/educated executives are the best change agents - they are the leaders in their organizations and define the Tone at the Top and the organizational culture. Compliance Officers in every survey emphasize the importance of the Tone at the Top as the main driver for an integrity culture in the organization. Subsidized implementation of Compliance and Integrity Centers make the awareness building and training affordable for companies and bring the entrance barriers down.

Active Compliance and Integrity Centers will positively impact the private sector environment. They will improve the capacity of local businesses to fight corruption through targeted trainings, the sharing of good practices and the other described activities.

The expert centers will provide key learning which will assist in the creation of Centers which foster meaningful and sustainable collaboration between local, regional and global stakeholders to empower businesses to improve effectiveness of anti-corruption efforts and bring about enhanced transparency and accountability.

The creation of a systematic support by expert centers for establishing compliance and integrity centers at universities/business schools will be a new effort to bring academia and Business together in the fight against corruption. It would include the creation of platforms/programs that will leverage the tools and capabilities of academia, practitioners, and businesses, and advance the effectiveness of anti-corruption efforts through an impactful collaboration. 


\subsubsection{Key objective of the project}

Building on existing designs and infrastructures created by PRME business schools to combat anti-corruption and foster compliance and integrity, a core group of subject matter experts will develop a blueprint for establishing mixed academic and business anti-corruption capacity building and training centers at universities/business schools.

In emerging markets, anti-corruption efforts are mostly limited to subsidiaries of international companies and few big local companies. Many companies do not have the resources to fight endemic corruption and often play along the traditional corrupt "rules." They may even view them as a competitive advantage against large international firms. They urgently need support, starting with awareness building and training in practice oriented anti-corruption tools.

To offer effective support and training, academia and business have to work hand in hand: Academic concepts are interesting but alone not helpful, companies seek practical tools ready to be implemented. Thus, theoretical aspects and concepts need to be complemented by insights from the real business environment. Mixed academia-business projects are a proper solution to that problem.

The success of the proposed project can be measured by the quantity of new centers constituted and existing academic centers modified into mixed academic-business centers and courses offered by these centers, the number of course-participants, the participants' evaluations of the course quality and the evolution of these numbers and quality evaluations.

Additional possible KPIs are the number and evaluated quality of the other listed activities which complement the courses.

\subsubsection{Key activities planned}

PRME organizes a one or two day conferences where the business schools/ universities with working "expert" AC centers present their objectives, organization, processes, funding, and activities. Institutions interested in $\mathrm{AC}$ and in bringing academia and business in an own center together can find on this "market place" concepts and ideas on how to develop their own compliance and integrity centers. Further advice and implementation 
support will be given by the expert centers on bilateral bases. An international network and collaboration of AC Centers will be built among the expert centers and new centers.

The expert centers will present their blueprints for building academicbusiness-led anti-corruption capacity building and compliance and integrity centers at universities/business schools and the objectives, standard course material, a proposal for cooperation between business and academia, budgets/financing needs overviews and human resource needs, as well as funding models for setting up anti-corruption centers.

Roll-out (follow-up) activities will focus on testing proof of concept in each country through the expert centers which:

- Develop evidence-based and results-oriented approaches for designing and delivering training programs customized to address integrity concerns and corruption risks with collaborating corporations, public agencies and nonprofit organizations in target countries;

- Further the knowledge of best practices in the application of integrity tools, anti-corruption interventions, and integrity training in the different sectors and organizations;

- Facilitate Anti-Corruption Workshops and best practice exchange;

- Organize conferences on Anti-Corruption strategies and challenges;

- Create a platform for Executives, Compliance Professionals and Academics to cooperate and assist/support the process of developing the activities.

The close link to the UN Global Compact provides access to relevant global companies especially those active in emerging markets and other stakeholders which enable the project to address the specific the needs of local institutions in ways that enable these initiatives to maximize their impact. The Working Group will need moderate funding to launch the project. The PRME Secretariat will manage the funds required, organize the cooperation and oversee the activities of subject matter experts, create a platform for ongoing exchange of good practices, and organize annual events that facilitate productive exchange between academic and private sector institutions and other key stakeholders. 


\subsubsection{Other projects}

a) Ongoing activities like serving as panelists and speakers in anticorruption courses and at conferences of AC WG members. One example is the webinar in September 2020 organized by the IIHMR University in Jaipur, India on ethics and transparency in the Health Care Sector with the moderator and three panelists (among others) from our Working Group.

Other examples are papers jointly written by WG members, books edited by WG members with chapters (among others) written by WG members as well as conferences on anti-corruption organized by Working Group members in Switzerland, Qatar, and Argentina.

b) Additional, new activities include:

a. Organize regular meetings of our working group, inviting other interested academics. During these meetings papers or other recent works can be shortly presented and afterward discussed. The expectation is that these meetings provide the opportunity to originate new works and collaborations.

b. Develop a short course on transparency and integrity in the health sector which will be taught by the group members online.

c. Develop a core curriculum for an anti-corruption course along the lines of Ron Berenbeim's course taught in China for advanced students.

We aim at maintaining a committed core Working Group. The existence of a committed core group is deemed essential for achieving concrete output. 